\title{
القيم والأخلاقيات المهنية في الخدمة الاجتماعية
}

\author{
أستاذ دكتور/ مدحت محم أبو النصر \\ رئيس قسم المجالات بكلية الخدمة الاجتماعية جامعة حلوان ( السابق ) \\ دكتوراه من جامعة Wales ببريطانيا \\ دكتوراه فخرية من المجلس العلمي لعلماء ومبدعي مصر والعرب \\ رئيس لجنة ترقية الأساتذة قطاع الخدمة الاجتماعية - المجلس الأعلي للجامعات \\ أستاذ زائر بجامعة . C.W.R. \\ أستاذ معار بجامعة الإمارات العربية المتحدة (سابقا) \\ رئيس قسم العلوم الإنسانية - كلية شرطة دبى (الأسبق) \\ جائزة أفضل كتاب من الإمارات لعام 1996 وجائزة الابداع العربي 2018
}

\section{مقدمة :}

بسم الله الرحمن الرحيم يقول الله سبحانه وتعالي في كتابه الكريم ( تلْلكَ حُدُودُ اللَّهِ ٍَّ وَمَنْ

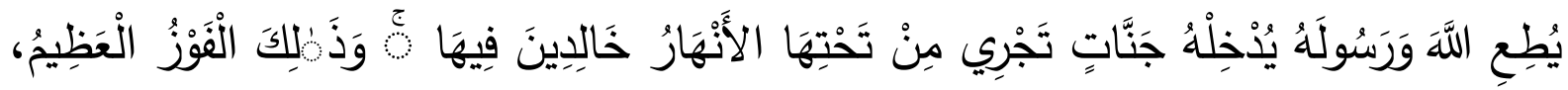




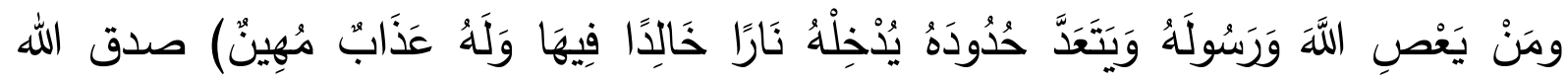

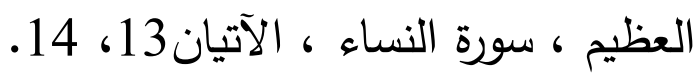

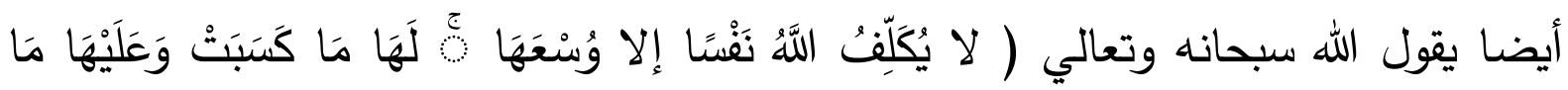

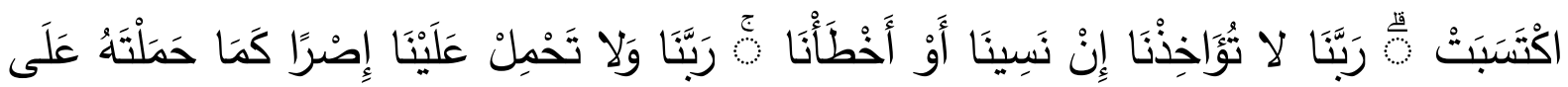

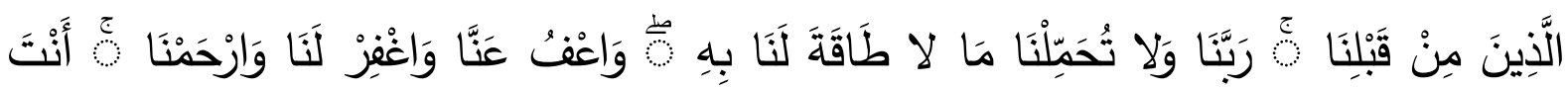

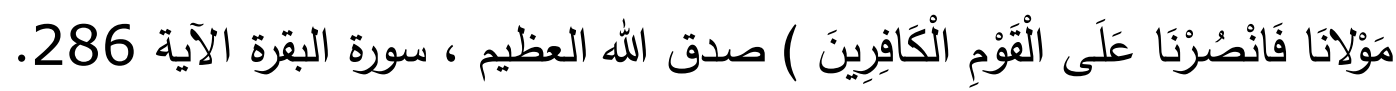
أيضا قال رسول الله صلي الله عليه وسلم : " إنما بعثت لأتم مكارم الأخلاق ". وعن عبد الله بن عمرو بن العاص رضي الله عنهما أن رسول الله قال : " أربع إذا كن فيك فلا عليكا لإنيك

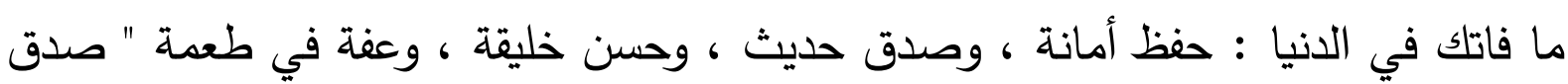
رسول الله صلي الله عليه وسلم. لقد بعث الله للبشرية خاتم الأنبياء والمرسلين سيدنا محم عليه أفضل الصلاة والتسليم ليتمم

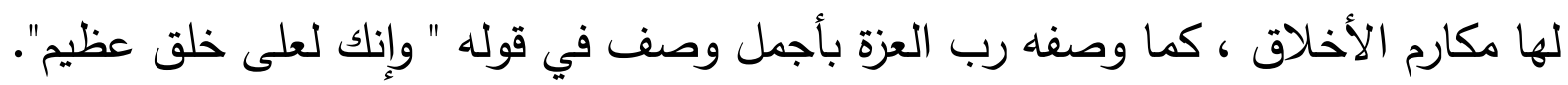

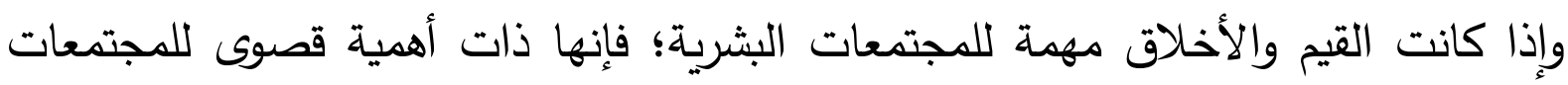
الإسلامية كون الواجب الثرعي يلزمها الاقتتاء بقدوتها وقائدها حمح صلى الله عليه وسلم. ويعتبر موضوع القيم الأخلاقية من المواضيع القديمة الحديثة إذ لا تكاد توجد أمة من الأمم ليس لها قيم Values وأخلاقيات Ethics تتنهجها في تعاملها فيما بينها أو مع غيرها. وبالرغم من التباين والاختلاف بين الاجناس والأعراق والديانات إلا أن هناك معايير أخلاقية

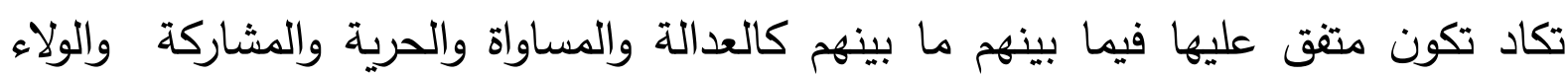
والانتماء ...

أيضا لا توجد مهنة Orofession أو منظمة Organization من منظمات المجتمع ليس

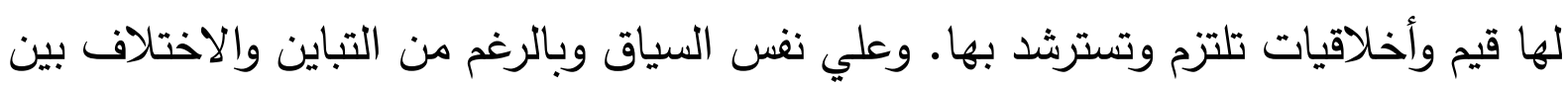

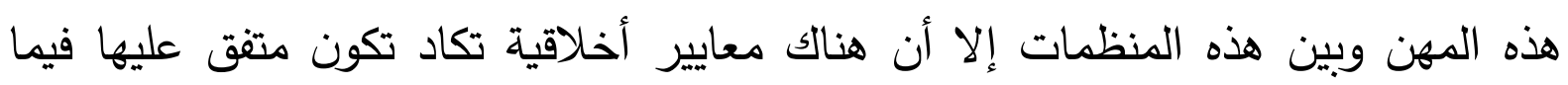
بينهم كالصدق والكفاءة والنزاهة والمهنية وعدم التمييز السلبي ل... 
وثمة ارتباط أصيل بين الإنسان والقيم سواء علي مستوي الفرد أو الهجتمع. فكما عرف

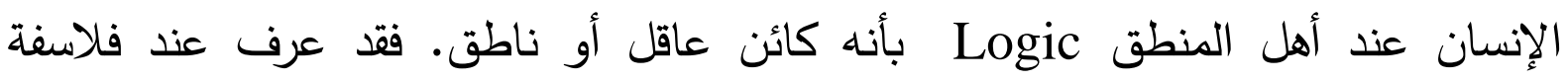
الأخلاق Ethics Philosophers أن الأنسان كائن قيمي ، ومن ثم فلان الأن يمكن تصور الإنسان العاقل دون قيم. ومن ثم فلا يمكن تصور الإنسان العاقل دون قيم. ويري علماء علم النفس Psychology التحليلي مثل Sommors وفلوجل Flugel أن القيم ترتبط Super Ego Suciological (الضمير). ومن منظور سوسيولوجي فإن الإنسان كائن اجتماعي ، ومن ثم فلا يمكن تصور الإنسان في تفاعله مع الآخرين دون قيم تضبط هذا التفاعل. أيضا ينظر بعض علماء علم الاجتماع إلي أن القيم تعتبر حقائق أساسية هامة في البناء الاجتماعي Social Structure ، وهي لذلك تعالج من وجهة النظر السوسيولوجية علي أنها عناصر بنائية تثتق من التناعل الاجتماعي بين الناس في المجتمع.

وقد عبر الدفكر الفرنسي روجيه جارودي Roger Garaudy في كتابه الإسلام دين

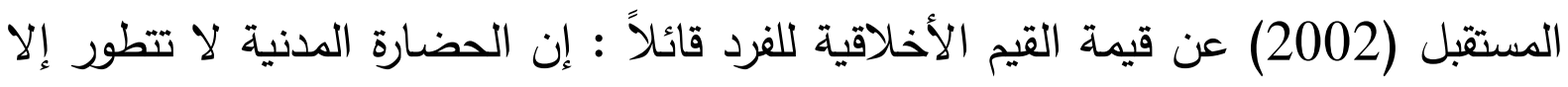
إلى هلاك الإنسانية وفنائها ولا سبيل للخروج من ذلك إلا بالتمسك بالقيم الروحية

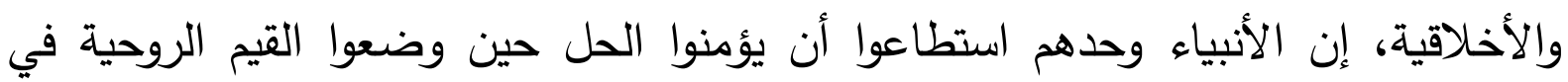

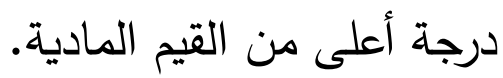

ويهدف البحث الحالي إلي توضيح أهمية القيم والأخلاقيات المهنية في الخدمة الاجتماعية

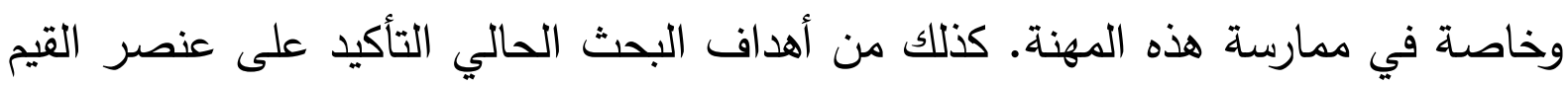

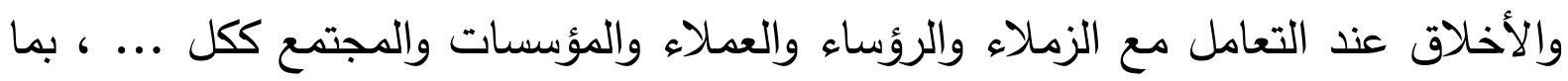
يساهم في خلق مناخ عمل صحي وثقافة مهنية موجبة، تساهم بدورها في قلة التقاعل السلبي وانخفاض عدد الشكلات وتقليل معدلات المخاطر بين الأطراف السابقة .. وبالتالي

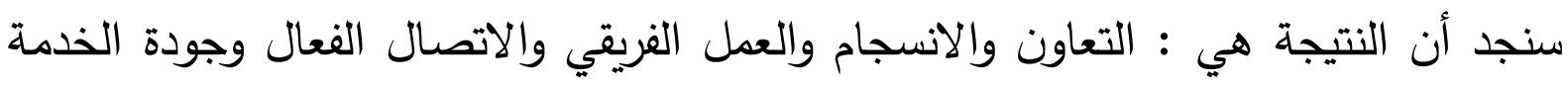
وتحقيق أهداف مهنة الخدمة الاجتماعية... 
والبحث الحالي كما هو واضح من عنوانه سوف يلقي الضوء علي ماهية القيم والأخلاقيات بصفة عامة والمهنية بصفة خاصة في الخدمة الاجتماعية ، ويعرض لأهميتها ومبررات دراستها ومصادرها وأمثلة لها...

\section{القيم والأخلاقيات : - (القيم}

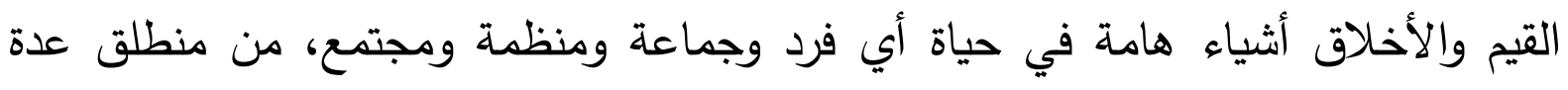

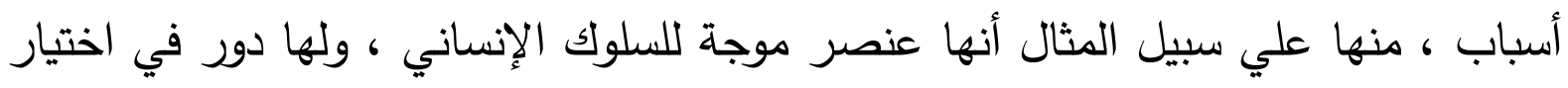

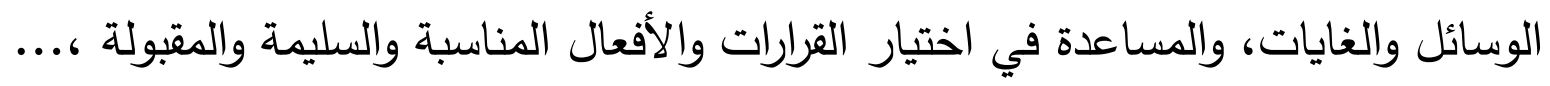
وبكلمات أخري فإن القيم والأخلاقيات تتجلي أهميتها في كونها وسيلة لترشيد السلوك

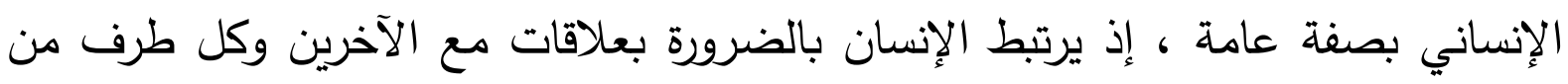

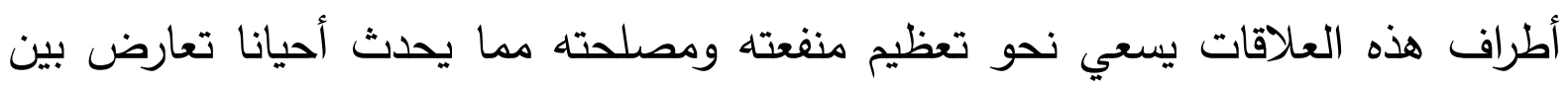

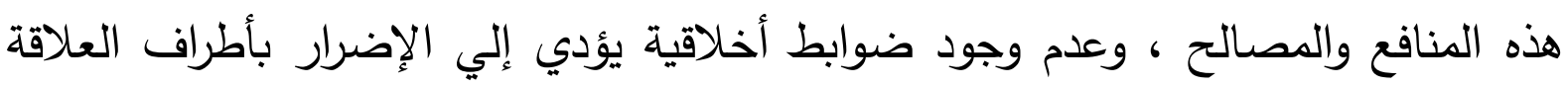

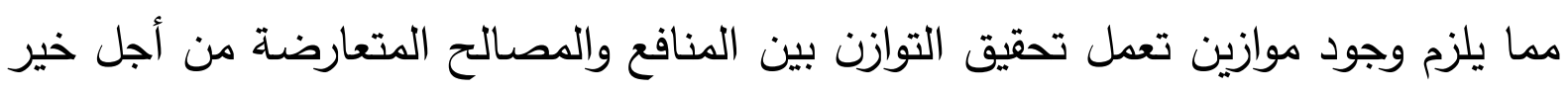
الجميع ، وهذه الموازين هي القيم والأخلاقيات.

ففي غياب الأخلاق يصبح الوصولي المتسلق رجلاً رائعاً مميزاً ... وفي غياب الأخلاق

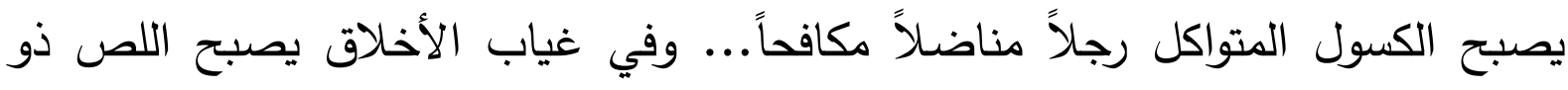

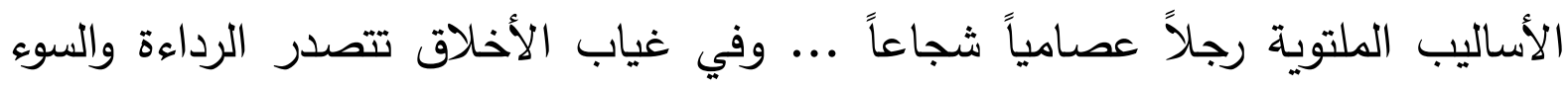

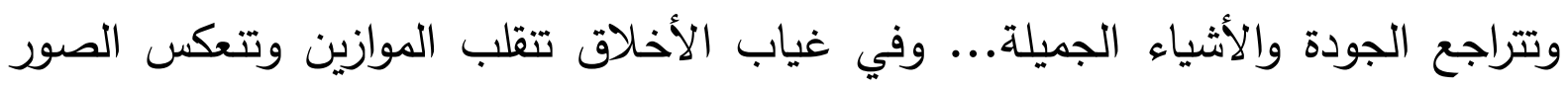
ويختلط الحابل بالنابل ...

وحين تغيب الأخلاق يصبح من السهل جداً هضم حق موظف مخلص مجتهد طوال الوقت

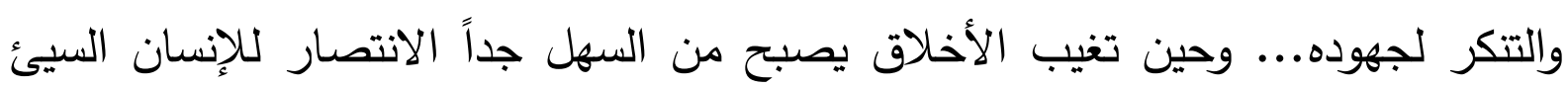

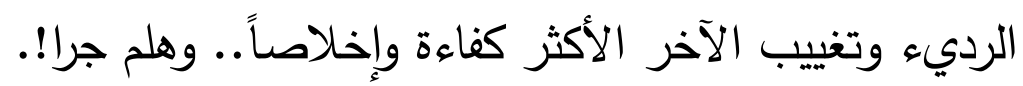

هذا ويعتبر موضوع دراسة القيم والأخلاقيات من الموضوعات لصيقة الصلة بالفلسفة Philosophy للدراسة التجريبية في علوم ومهن أخري. 
ولا شك في أن القيم والأخلاقيات في كل مجتمع هي نتاج تطور تاريخي طويل .. لهذا فهي

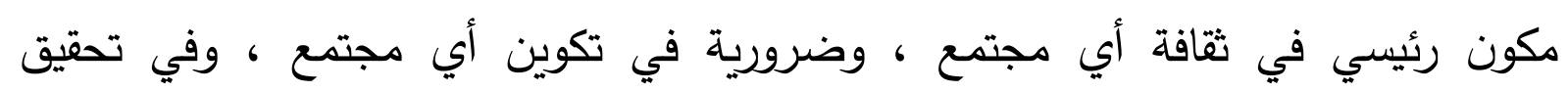
الاستقرار فيه ، بل وتطوير هذا المجتمع وتحسين جودة الحياة فيه ل...

القيم Values

هناك تعريفات عديدة لمصطلح القيم ، نذكر منها : 1- يري وليم جوردن William Gordon لاي كثير من الناس في المجتمع.

2- القيم هي المبادئ والمقاييس التي نعتبرها هامة ولغيرنا ـ ونطالب بتحقيقها.

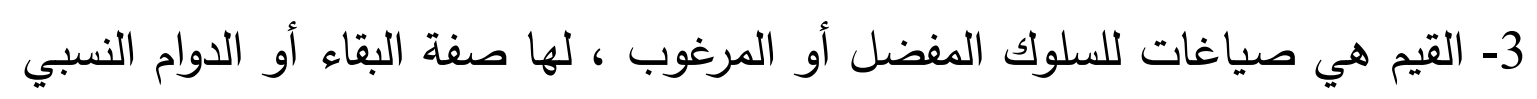

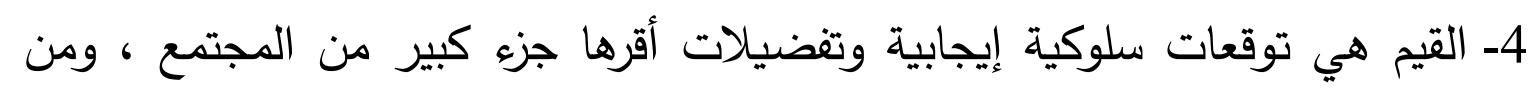

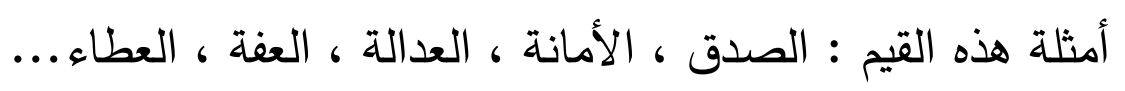

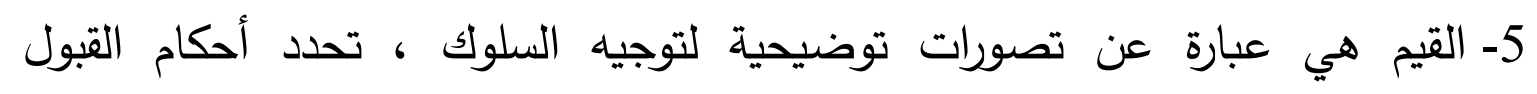

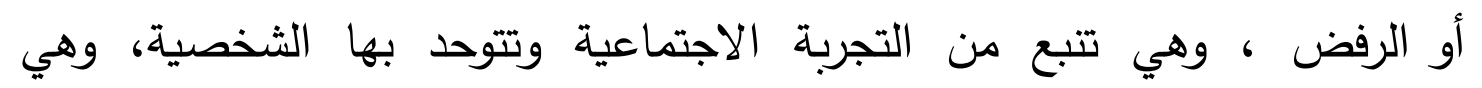
عنصر مشترك في تكوين البناء الاجتماعي والثخصية النزردية.

6- القيم تعكس البيانات الثقافية والمعتقدات والقواعد والعادات والبديهيات الاجتماعية ، والتي تلعب دورًا أساسيًا في تحديد السلوكيات المرغوبة أو المبات المرفوضة.

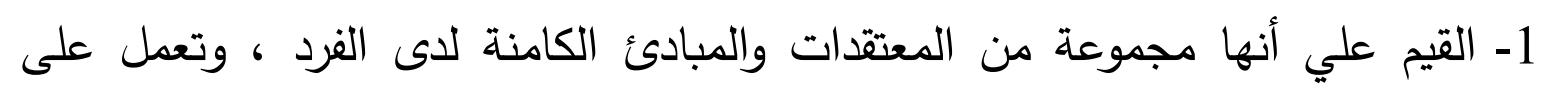

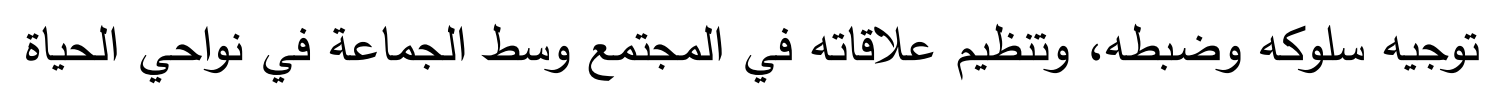

$$
\text { المتعددة" ( ماجد الزيود : } 2006 \text { ). }
$$

2- القيم هي مجموعة من المتتدات والمعايير المستمدة من القيم الدينية والإنسانية والاجتماعية العليا ، وتعتبر دليلا للأدوار الاجتماعية من أجل تحقيق الأهداف.

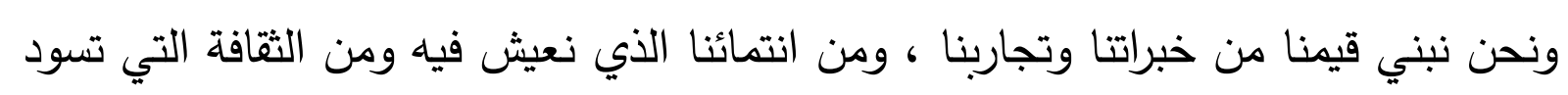

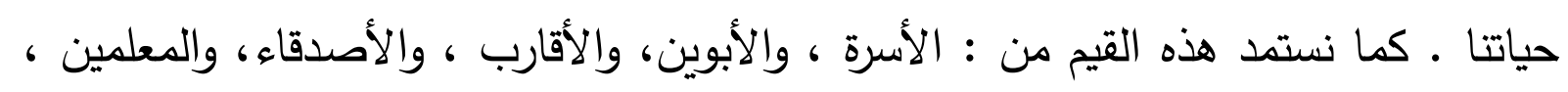


والمربين، ووسائل الإعلام ، وتستقر هذه القيم والمعايير في العقل الباطن ـ وتعكس القيم

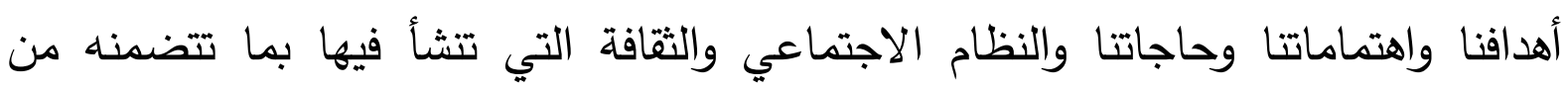
نواحي دينية واقتصادية وعلمية . ويري علماء النفس أن القيم شيء هام في حياة أي إنسان، بحكم أنها توجه وترشد السلوك

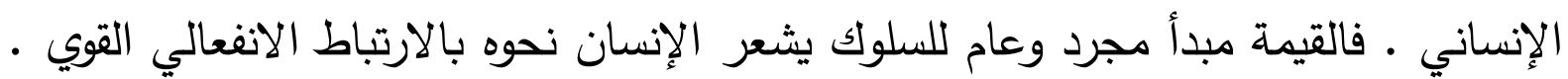

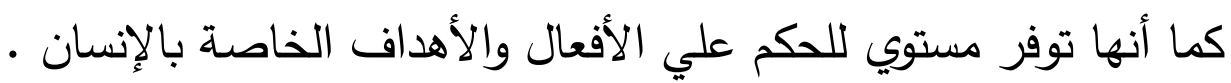
وبكلمات أخري ، فإن القيم لها دور رئيسي في توجيه السلوك الإنساني ، وتحفيز الفرد

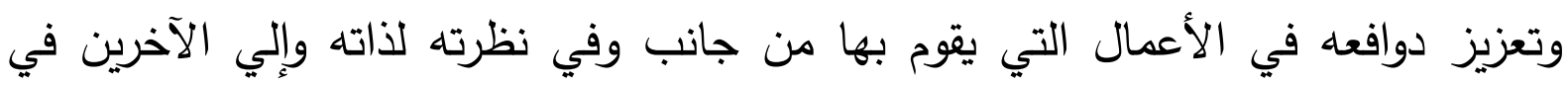
ضوء الاطار القيمي الذي يؤمن به ويتمثله في سلوكه وبما يحقق تنظيم الحياة الاجتماعية واستقرارها ( عبد اللطيف خليفة : 1992 ).

وفي ضوء ما سبق يمكن أن نقول أن القيم هي المبادئ والمقاييس التي تعتبر هامة لنا

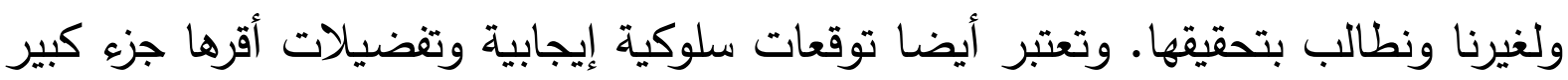
من المجتمع ومن أمثلة هذه القيم : الدساواة ، والتسامح ، والصدق ، والعدالة ، والنزاهة ، والولاء والانتماء ، والعفة ، والعطاء ، والمواطنة، والحرية الثخصية ، والاستقلالية الذاتية ،

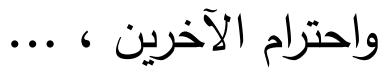
تصنيف القيم :

إن تعدد وتتوع تصنيفات القيم يعكس التتوع الاجتماعي والثقافي لأي مجتمع ، ويعكس أيضا

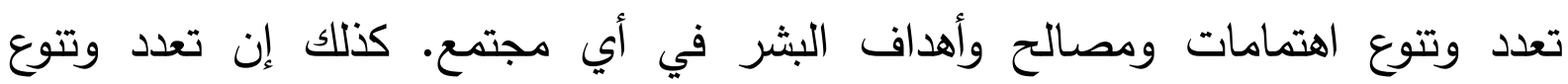
تصنيفات القيم يرجع إلي اختلاف تفضيلات الأفراد وتباين الأحكام التقديرية لهظاهر السلوك الإنساني وطبيعة النشاط الواقعي له ( انظر : وجيهة ثابت العاني : 2014 ). ومن محاولات تصنيف القيم ، التصنيف التالي : 1- تصنيف القيم حسب المحتوى أو الموضوع أو المجال. 2- 2 3- 3 ت تصنيف القيم حسب العمومية. 
4- ت تصنيف القيم حسب ديمومتها.

ومن أمثلة القيم حسب محتواها أو موضوعها أو مجالها كالتالي :

$$
\begin{aligned}
& \text { 1- القيم القومية الوطنية. } \\
& \text { 2- القيم الاجتماعية. } \\
& \text { 3- القيم الاقتصادية. } \\
& \text { 4- القيم السياسية. } \\
& \text { 5- القيم الإنسانية. } \\
& \text { 6- القيم المعرفية العلمية. } \\
& \text { 7- القيم الدينية. }
\end{aligned}
$$

وتجدر الإثارة إلي أن العلوم الاجتماعية تميز بين نوعين من القيم هما :

$$
\text { 1 - قيم الوسيلة : }
$$

وهي تعد معتقدا يفاضل فيه الفرد بين سلوك وآخر ، الصدق أفضل من الكذب ، الثجاعة أفضل من الجبن ، الكرم أفضل من البخل.

$$
\text { 2- قيم الغاية : }
$$

وهي تتمثل بمجموعة القيم التي تحدد لنا الغايات المثلي التي تسعي لتحصيلها وذلك لارتباطها بتحقيق المجتمع المدني الحديث .

ويمكن الإثشارة إلي أهم قيم العمل العامة في الهجتمعات الحديثة والدعاصرة علي سبيل

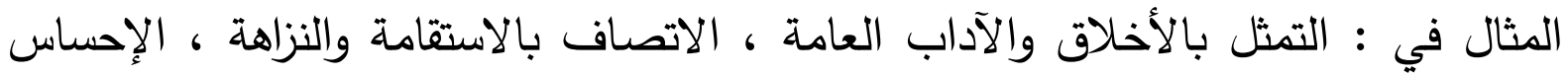
والثعور بالمسئولية ، احترام القانون والامتثال للأنظمة والمبادئ ، احترام حقوق الآخرين

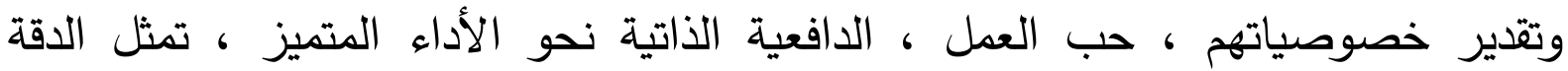
والانضباط سلوكيا. وحيث تعد الإطار الموجه لحياة وسلوك الأفراد ، لذا تقوم القيم بدور كبير جدا في التأثير علي الاتجاهات والدافعية نحو العمل والإنجاز في المجتمع. وهنا تجدر الإثشارة إلي أن مجموع القيم السابقة يعتبر المحرك الرئيسي لتطور ورقي

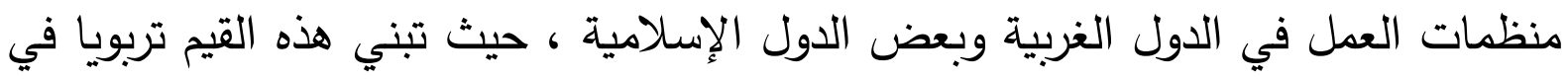

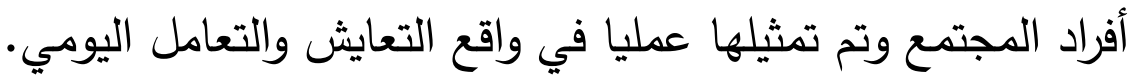




\section{: Ethics الأخلاقيات}

يرجع أصل كلمة الأخلاق إلي اللفظ اللاتيني Morals ، والكلمة اليونانية Ethos التي تعني أثكال التقاليد أو العادات الخاصة بالتصرفات. وهناك تعريفات عديدة لهصطلح

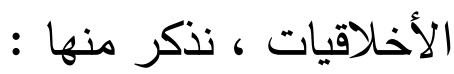

1- الأخلاقيات مصطلح يثير إلي فلسفة الصواب والخطأ في السلوك ، والتمييز بين ما

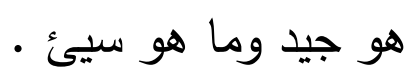

2- الأخلاقيات بأنها معيار أو مستوي أو قاعدة للسلوك بهدف إشاده وتوجيهه الوجهة

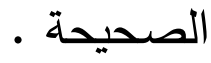

3- الأخلاقيات مصطلح متعلق بمسائل السلوك الصحيح والخطأ ، والصفات الجيدة

$$
\text { والسيئة للشخصيات ( Sarah Banks : } 2009 \text { ). }
$$

وعلم الأخلاق هو علم دراسة قواعد السلوك الصحيحة والخاطئة ، والصفات الجيدة والسيئة للشخصية. بكلمات أخري علم الأخلاق هو علم دراسة تصرفات الإنسان فيما يتعلق بالصواب والخطأ . بمعني أن علم الأخلاق هو علم يهدف إلي وضع قواعد للسلوك

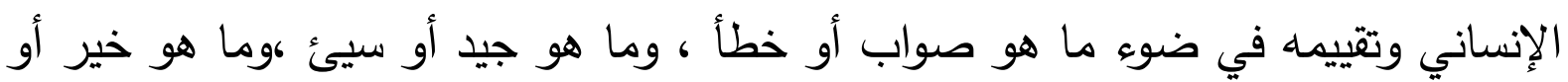
شر ، وذلك بهدف أن يحيا الإنسان حياة فاضلة.

ويمكن تحديد موضوعات علم الأخلاق في: القيم والأخلاقيات والفضائل ومعايير السلوك. هذا ويمكن أن نقول أن علم الأخلاق أحد العلوم المعيارية الذي يهتم بدراسة أخلاق وقيم

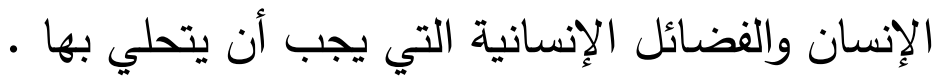

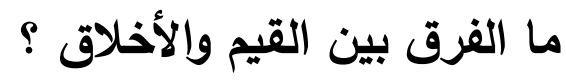

القيم مكون داخلي ومعنوي وعاطفي وعقائدي ، بينما الأخلاق أقرب إلي السلوك والممارسة

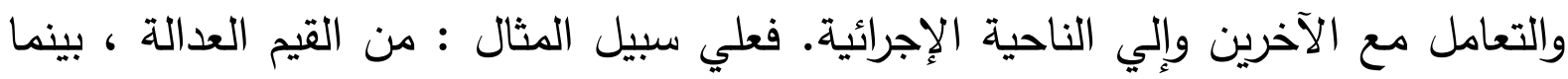
عدم التمييز السلبي بين الناس هو أخلاق. ومن القيم العطاء ، بينما التبرع بالمال للفقراء

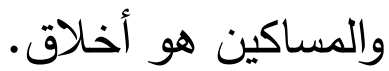


القيم أكبر وأعم من الأخلاق ، أي أن الأخلاق تأتي تحت مظلة القيم. والأخلاق تستند

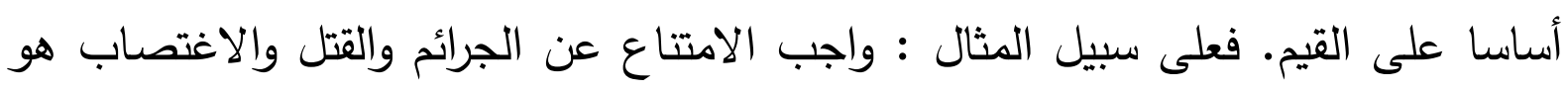
من الأخلاق. وذلك يستند علي قيم الرحمة والصدق والإنسانية...

القيم هي كل ما له قيمة، وهي تثمل أشياء كثيرة ، والأخلاق جزء منها، بينما الأخلاق منها

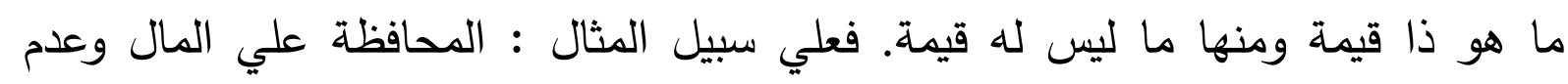

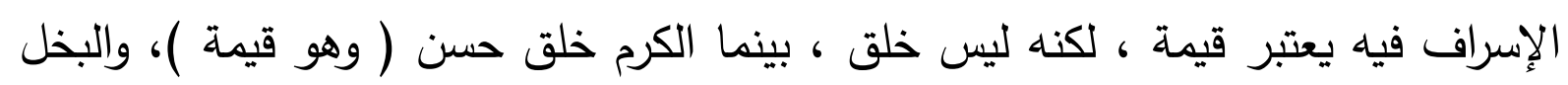
خلق ذميم ( وهو ليس قيمة ).

القيم كلها حسن ، أي تختص بالأمور الحسنة. بينما الأخلاق تثمل الحسنة والسيئة ، أي

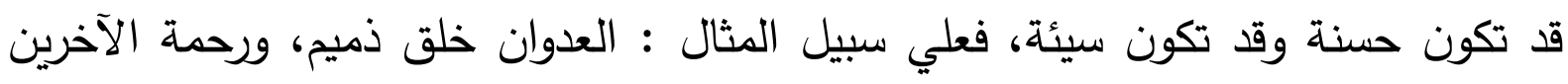

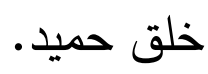

\section{مصادر القيم والأخلاقيات العامة في أي مجتمع :}

تستمد القيم والأخلاقيات العامة في أي مجتمع أصولها من المكون الديني والاعتقادي

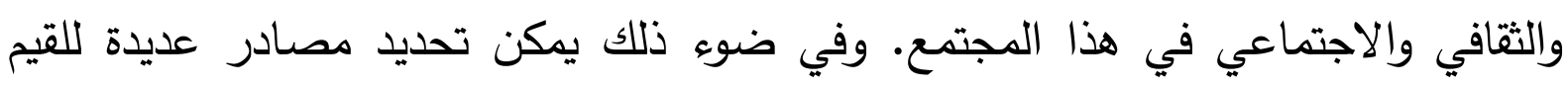

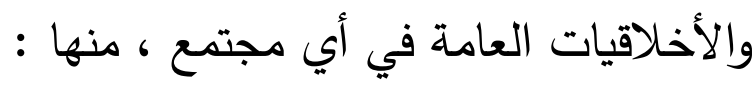

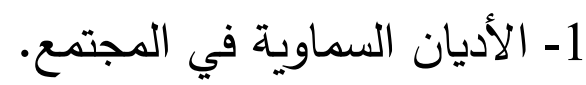

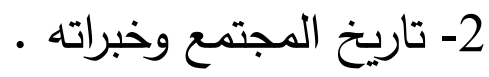

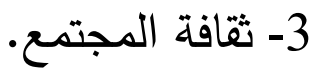

4- القبيلة والعشيرة والعائلة والأسرة .

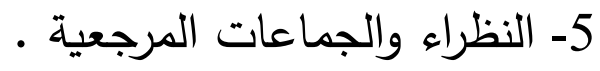

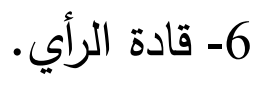

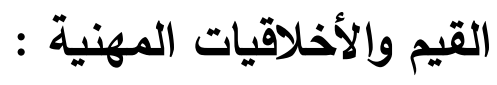

نظرا لأهمية الجوانب الأخلاقية لأي مهنة قامت معظم هذه المهن بوضع مواثيق شرف أو

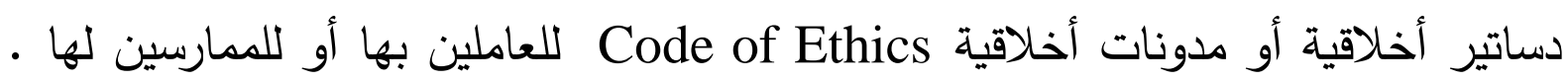


Code Of كذلك قامت بعض المنظمات بوضع مواثيق شرف أو دساتير أخلاقية لنفسها Conduct

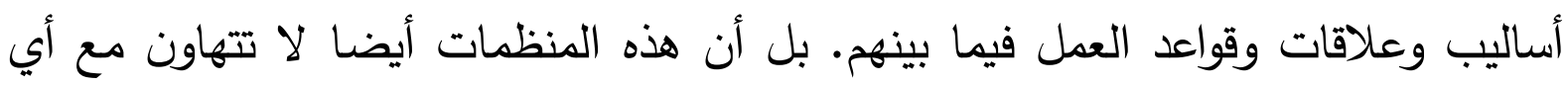
من العاملين يثبت عدم التزامه بهذا الميثاق.

نقطة أخرى هامة وهى أن يتم توجيه هذه المواثيق أو المدونات في كل منظمة نحو القضايا

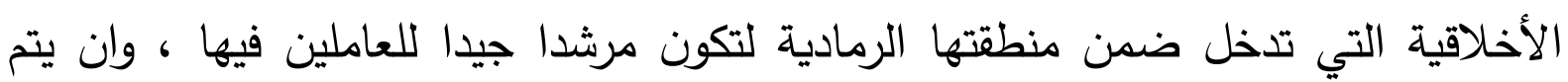
مراجعة دورية لعمليات وأنثطة المنظمة وسلوك مديريها وخاصة المستفيدين من خدماتها أو المستهلكين للسلع التي تنتجها.

إن اهتمام منظمات المجتمع باختيار الديرين والعاملين والأعضاء والمتطوعين علي أساس متوازن من الكفاءة والخصائص الأخلاقية ، يضمن لهذه الفئات أن يكونوا قويا لتعزيز سمعة والإين

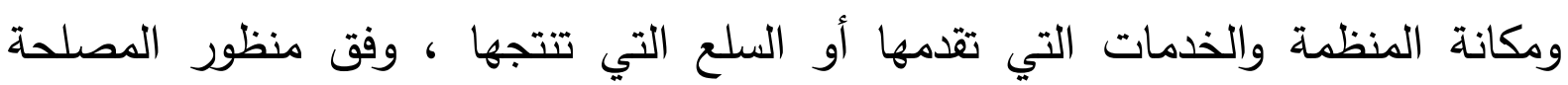

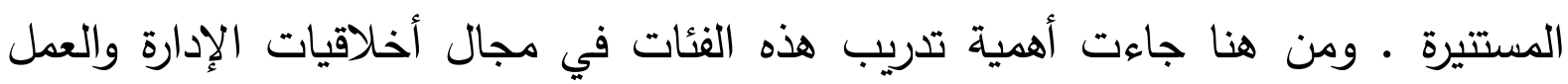
ليكونوا قوة داعمة لهذه الأخلاقيات. إن المنظمات التي وضعت لنفسها مثل هذه المدونات الأخلاقية أو مواثيق الثرف تعبر عن درجة وعيها الإنساني والمهني ، ومحاولة منها للارتقاء بمسئولياتها الاجتماعية والتزاماتها

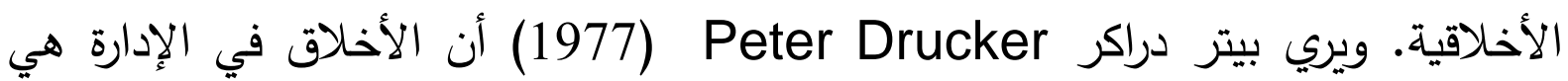

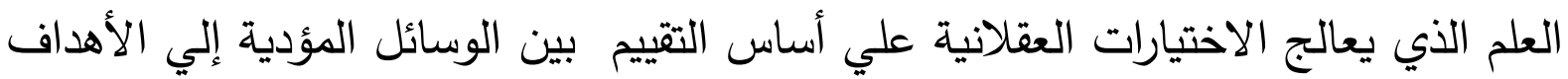

إن الضوابط الأخلاقية في أي مهنة تثكل العمود الفقري لأي مهنة ، ولأي منظمة تمارس بها هذه المهنة. والخلل في القيم والأخلاقيات كاف بهام أي مهنة وأي منظمة ل...إن الالتزام بالأخلاقيات يصحح أي خلل في الممارسات المهنية وفي الحياة عموماً. والقيم والأخلاقيات المهنية Professional Values \& Ethics هي قيم وأخلاقيات خاصة بالمهن أو بالمنظمات في المجتمع ، أي مرتبطة بالأشخاص المهنيين وبيئة العمل التي يعملون بها. ويشار للقيم والأخلاقيات المهنية بأنها معايير للسلوك تطبق علي هؤلاء الألياء الذين يشغلون مهنة

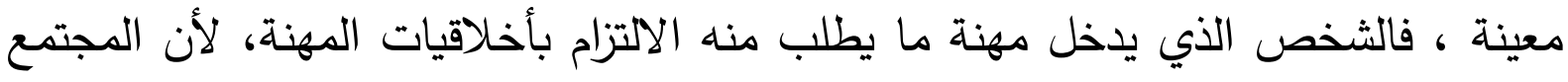


يجعله موضع ثقة في أن يقدم بضائع وخدمات ذات قيمة ، ولا يمكن أن تتوافر ما لم يكن

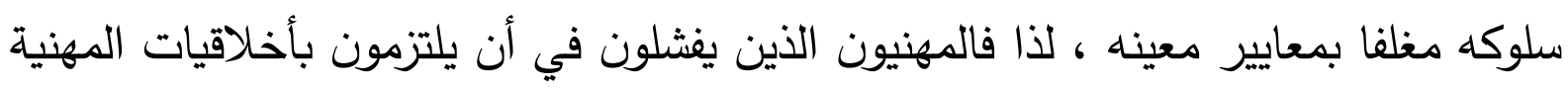

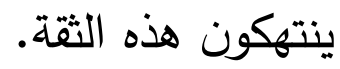

وهناك تعريفات عديدة لمصطلح القيم والأخلاقيات المهنية ، نذكر منها : 1- القيم والأخلاقيات المهنية هي مجموعة معايير للسلوك تطبق علي هؤلاء الذين

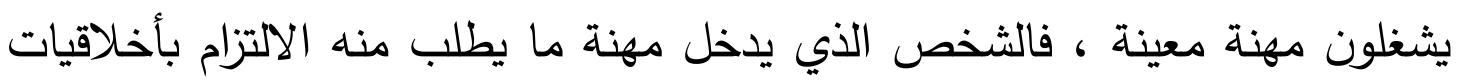

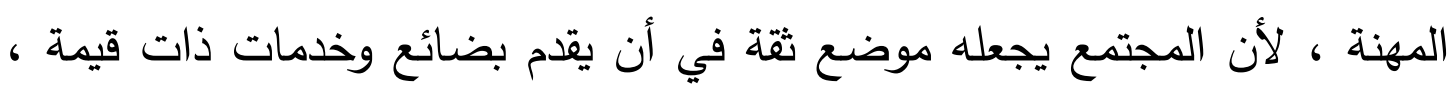

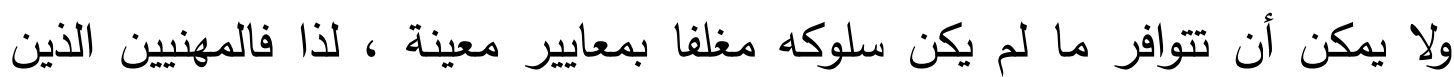

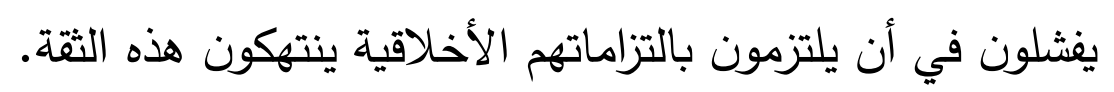
2- القيم والأخلاقيات المهنية هي مجموعة من المعايير والمبادئ التي تهيمن علي

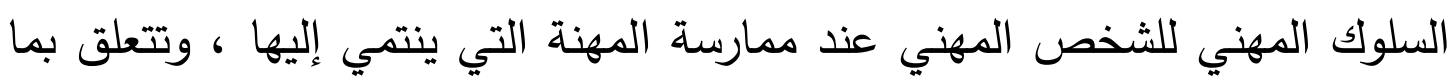
هو صحيح أو خطأ. 3- القيم والأخلاقيات المهنية تمثل خطوطا توجيهية للثخص المهني عند صنع واصدار

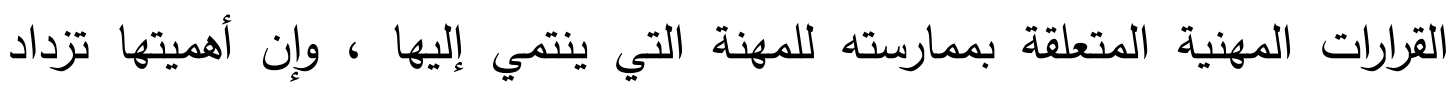
بالتناسب مع آثار ونتائج هذه القرارات. 4- القيم والأخلاقيات المهنية هي المنهجية للخيار الأخلاقي التي يتم من خلالها ما هو

$$
\text { جيد وما هو سيء. }
$$

5- القيم والأخلاقيات المهنية تثير إلي مسائل السلوك الصحيح والخطأ ، والصفات الجيدة والسيئة للشخصيات والمسؤوليات المهنية المرتبطة بالعلاقات في سياق المهنة أو العمل ( Sarah Banks : 2009 ).

مصادر القيم والأخلاقيات المهنية :

هناك مصادر عديدة للقيم والأخلاقيات المهنية ، منها :

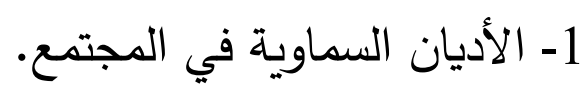

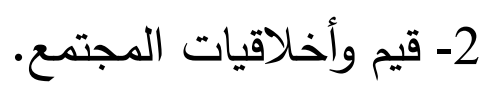
3- قيم وأخلاقيات أسر العاملين بالمنظمة. 


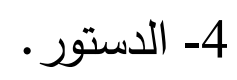

5- القوانين والتشريعات.

6- تعليمات ولوائح المنظمة.

7- خبرات العملية التعليمية.

8- خبرات الممارسة الميدانية أو العملية.

نقطة هامة أخري في هذا الثأن هو أن قيم وأخلاقيات المجتمع تمثل أساسا قويا للقيم والأخلاقيات المهنية ، لأنها أحد مصادرها ، ولأنها خلفية مسبقة في تكوين أفراد المجتمع

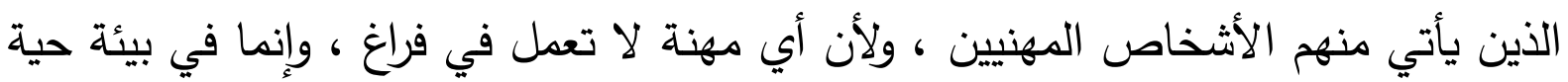
وديناميكية ومتفاعلة ، لابد من أخذ قيم هذه البيئة ومحدداتها الأخلاقية بنظر الاعتبار في قرارات أي مهنة الخدمة وعملياتها المختلفة لضمان قدر مناسب من تعاطف وتعاون

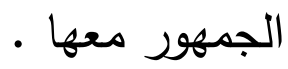

لماذا ازداد الاهتمام بالقيم والأخلاقيات المهنية في الوقت الحاضر ؟ في الوقت الحاضر كثر الحديث عن القيم والأخلاقيات المهنية ، وتتعالى الأصوات من أجل قيم وأخلاقيات المهن وقيم وأخلاقيات العمل برغم أنها قبل عقود قليلة فقط لم تكن موضع اهتمام ، كما لم تكن موضوعا نمطيا في أدبيات الغالبية العظمي من المهن - ومنهم مهنة الخدمة الاجتماعية - كما أن ما كتب عنها لا يخرج عن كونه اهتمامات ذاتية هنا وهناك ، من أجل إضفاء قدر من الاعتبارات الإنسانية والأخلاقية علي ممارسة المهن في مختلف المجالات.

ولكن مع تزايد الاتجاه نحو الأنسنة ، والمهنية ، والعولمة ، وزيادة وعي العملاء بحقوقهم ، ونظرا لحدوث أخطاء مهنية عديدة من قبل بعض الأشخاص المهنيين ، ونظرا لاتساع الانتقادات الموجهة لبعض المهن نظرا لعدم التزامها بالمهنية في بعض الأحيان ، وحرصها

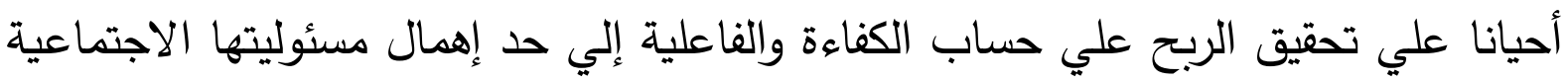
والأخلاقية ، ... لم يعد الصمت سهلا إزاء ذلك. لذلك زاد الحديث عن الرؤية القائمة علي القيم والأخلاقيات المهنية ، والتي لا تقل أهمية عن معايير الربح في نموذج جديد هو الهواء النموذج - الاجتماعي - الأخلاقي. 
وفي هذه الأيام كل الجامعات تقريبا تدرس موضوع الأخلاق ، وغالبا تطلب من طلبتها دراسة هذه المادة بسبب ما تعنيه من دلالة لحياتهم المهنية ومستقبل مجتمعنا. ونحن نؤكد بضرورة تدريس هذه المادة لطلاب الجامعة علي اختلاف تخصصاتهم وذلك لتوعية هؤلاء

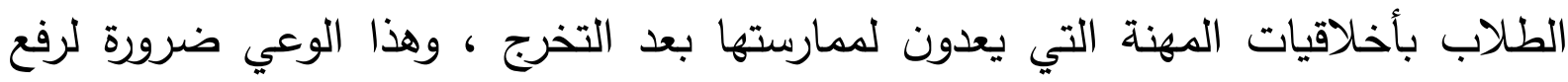
مستوي الأداء والإنجاز لمصلحة المهنة والثخص المهني والمتعاملين معه.

مبررات أهمية تدريس مادة القيم والأخلاقيات المهنية : قدمت سهام محمود العراقي (2000) عدد من المبررات لأهمية تدريس مادة الأخلاق المهنية

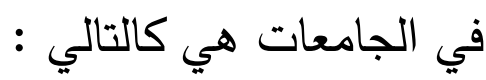
المبرر الأول : وهو التقدم المعرفي وازدياد الاتجاه نحو التخصص وما ترتب عليه من تقدم

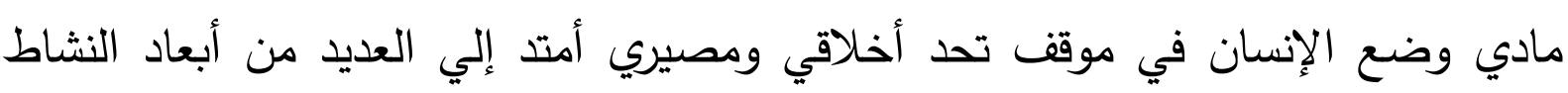

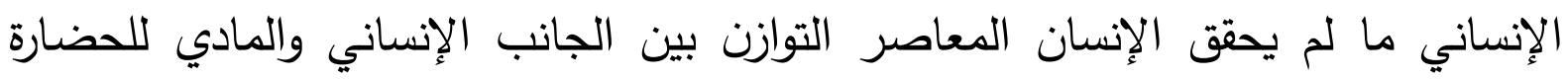

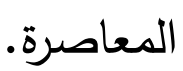

المبرر الثاني : هو التقدم التكنولوجي والاجتماعي وما ترتب عليهما من قضايا جدلية

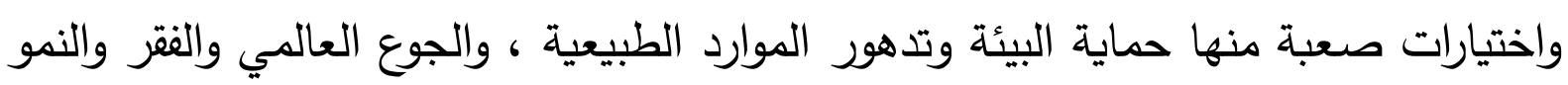

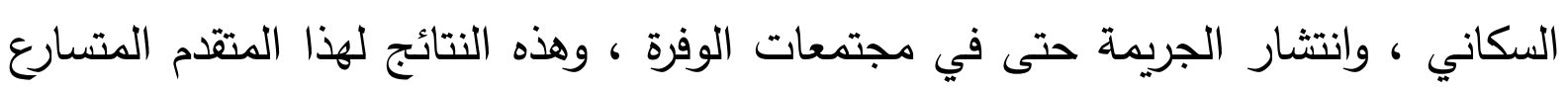
فاقت قدرة البشر علي التتبؤ بعواقبها الأخلاقية علي الحياة البشرية. المبرر الثالث : مبرر تربوي مرتبط بطبيعة البشر ، حيث أن الفرد في حياته اليومية وعلاقته بالآخرين بصفة مستمرة بامتحان قيمة الذاتية وضرورة الاختيار بين بدائل ممكنة

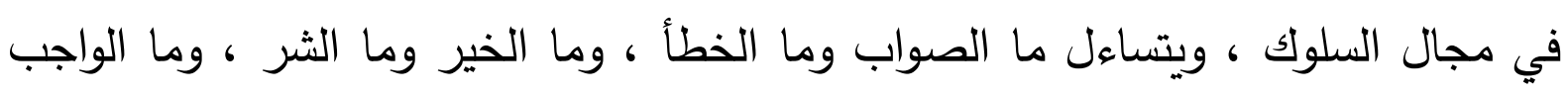

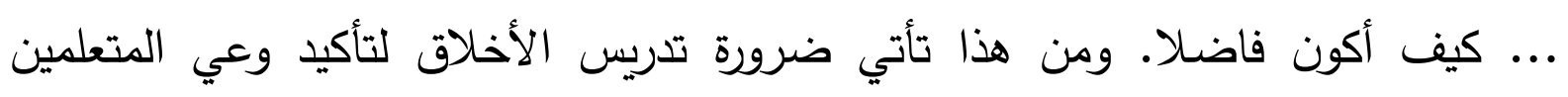

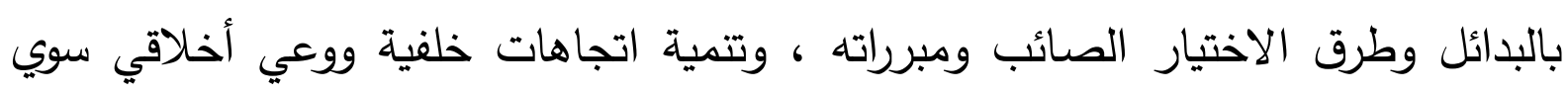

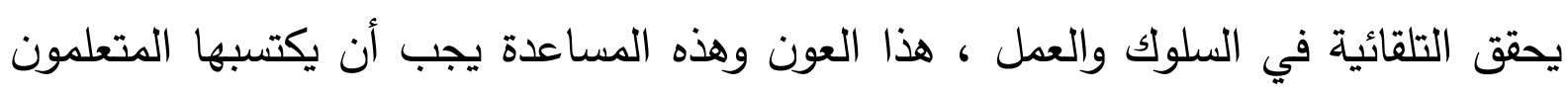

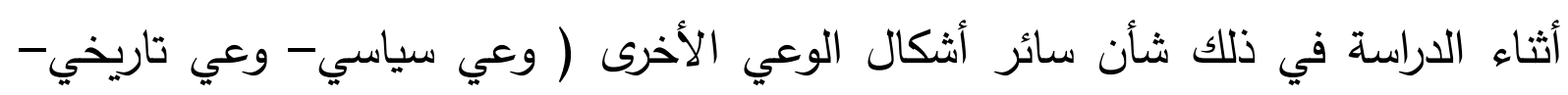
وعي علمي-وعي جمالي-وعي صحي ). 
المبرر الرابع :هو الديني، أو الذي يثتق من سؤال رئيسي عن الهذف من خلق الإنسان،

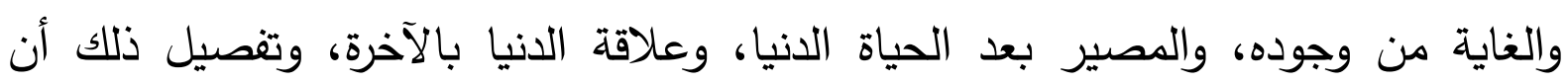
الإنسان مستخلف في الأرض، وهو مكرم علي غيره من سائر المخلوقات.

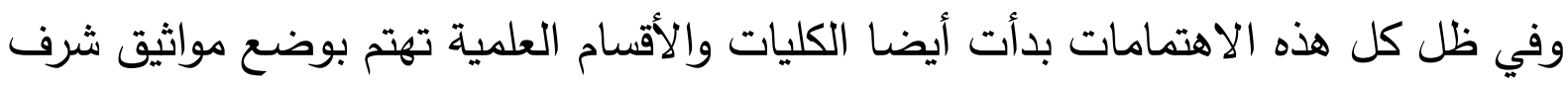
أو دساتير أخلاقية للمهن بالتعاون مع الوزارات المعنية والنقابات المهنية المختصة. أيضا

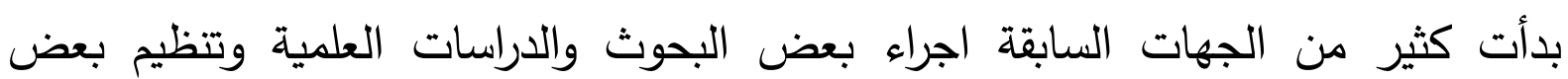

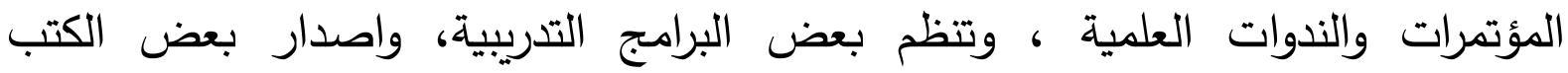
والدوريات في مجال القيم والأخلاقيات المهنية. الأديان السماوية والقيم والأخلاقيات :

Good قبل كل ذلك طالبت كل الأديان السماوية الإنسان أن يتصف بالأخلاق الحميدة Ethics ومن أمثلة هذه الأخلاق الحميدة : .

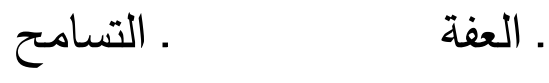

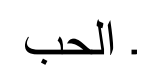

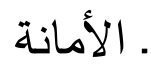
. مساعدة الآخرين التعاون

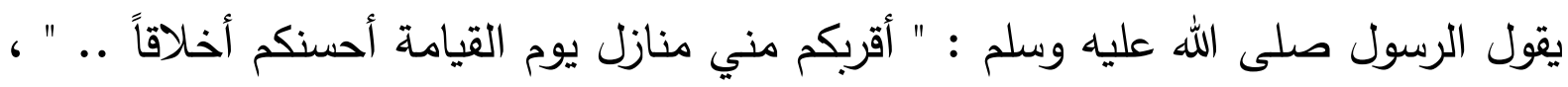
كذلك يقول : " اتق الله حيثما كنت ، وأتبع السيئة الحسنة تمحها، وخالق الناس بخلق حسن النال

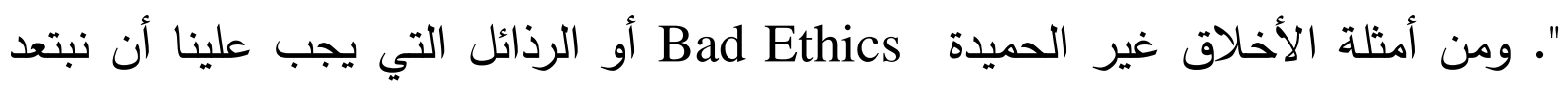
عنها، لأنها تبعدنا عن الله وتجعل الناس في حالة كراهية معنا:

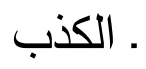

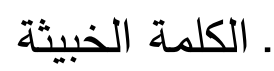

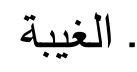
. الكراهية

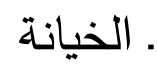

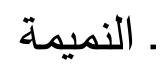

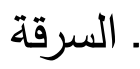

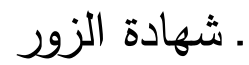

يقول الله سبحانه وتعالى : ( فمن يعمل مثقال ذرة خيراً يره ، ومن يعمل مثقال ذرة شراً يره ) صدق الله العظيم ، سورة الزلزلة آية 7 ، 8 . 
القيم والأخلاقيات المهنية في الذدمة الاجتماعية :

يقصد بالقيم والأخلاقيات المهنية في الخدمة الاجتماعية بالمعايير المهنية والمتتقدات المهنية المنبثقة من المثل العليا الدينية والإنسانية والمجتمعية التى يكتسبها الاخصائيون

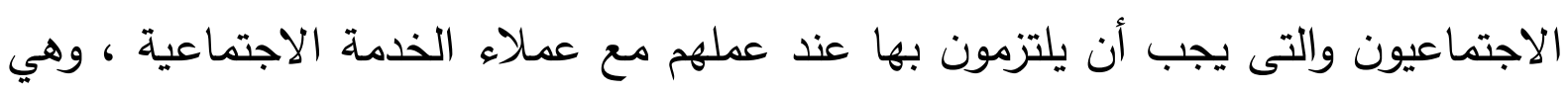
وتعتبر موجها للسلوك المهني للأخصائيين الاجتماعيين عند تحقيق أهداف المهنة.

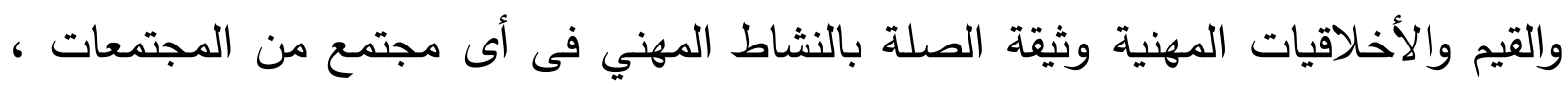

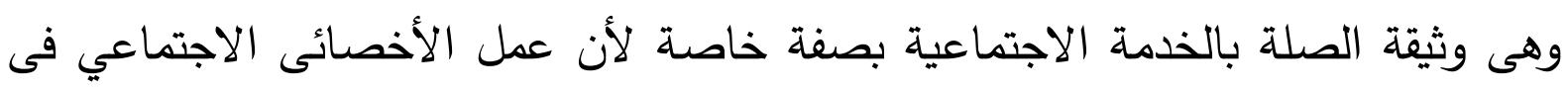
مجال العلاقات الانسانية جعله أثد حساسية للقيم الاجتماعية.

وقيمة الإنسان أسمى من مساعدته ، وتنقد المساعدة مصداقيتها اذا نالت من كرامة الانسان

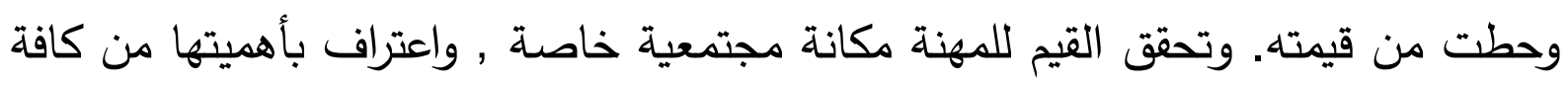

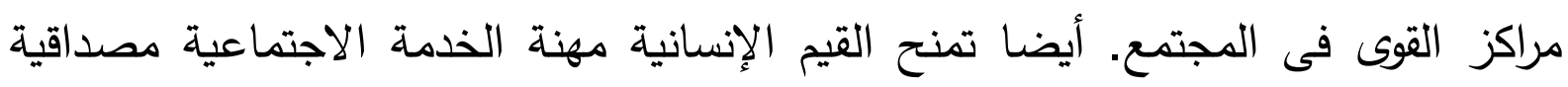

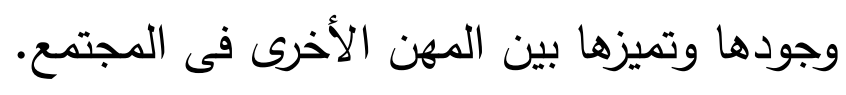

أنواع القيم في مهنة الخدمة الاجتماعية :

حدد كل من موراليز وشيفور Morales \& Sheafor (2000) ثلاثة أنواع رئيسية للقيم في مهنة الخدمة الاجتماعية ، هي كالتالي :

1- قيم مفضلة لاى عملاء الخدمة الاجتماعية ( مثل : العدالة ، والمساواة ،

$$
\text { والحرية....). }
$$

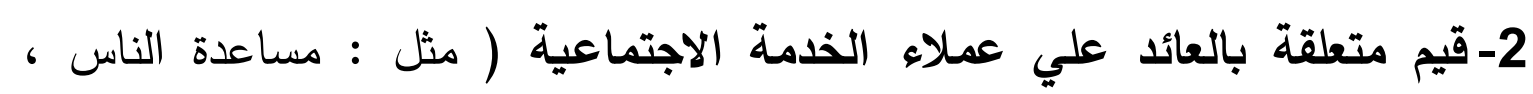

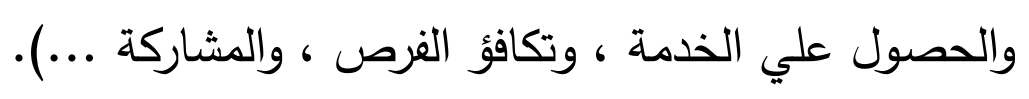

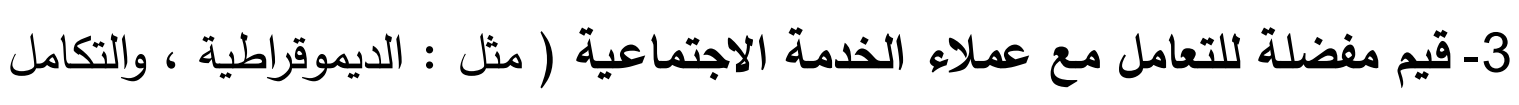

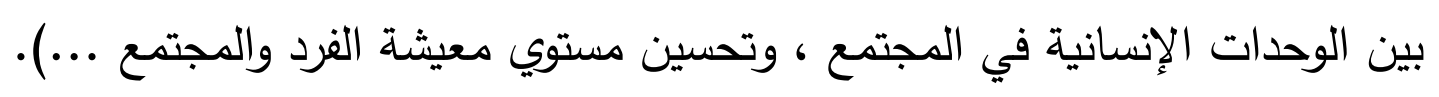
أيضا حددت باميلا لاندون Pamela Landon (1999) ثلاثة أنواع رئيسية للقيم في الإني

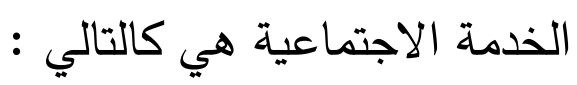




\section{1- قيم خاصة بالأخصائي الاجتماعي :}

فلكل أخصائي اجتماعي قيم خاصة به ، تم اكتسابها من خلال عمليات التنشئة الاجتماعية التي مر بها الأخصائي الاجتماعي في حياته. وهذه القيم قد تتفق أو تختلف مع القيم مهنة

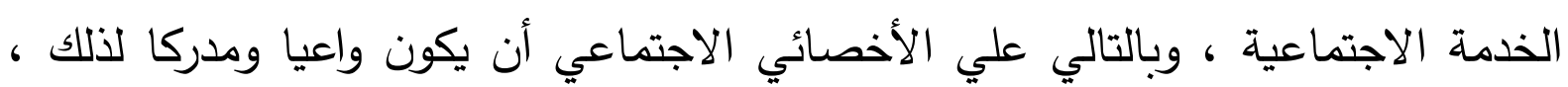

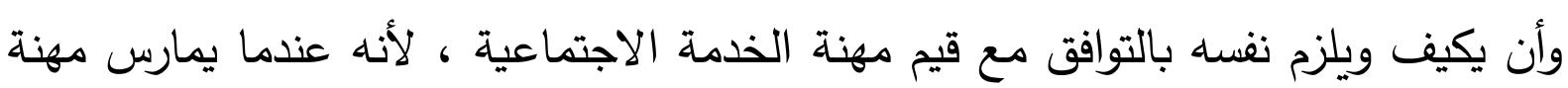
الخدمة الاجتماعية فإنه في ذلك الحين لا يمثل نفسه وإنما يمثل مهنة الخدمة الاجتماعية...

\section{2- قيم خاصة بمهنة الخدمة الاجتماعية :}

وهذه نطلق عليها مفهوم القيم المهنية. وهي القيم التي تؤمن بها مهنة الخدمة الاجتماعية

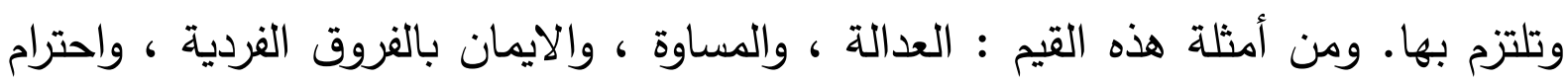
كرامة الانسان ، وأن لكل انسان عليه مسئولية تجاه ذاته والآخرين والمجتمع.... 3- قيم خاصة بعملاء الخدمة الاجتماعية :

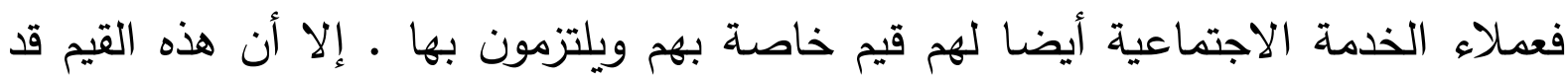
تختلف فيما بين العملاء ، وكذلك قد تختلف عن قيم الأخصائي الاجتماعي. وعلي الأخصائي الاجتماعي التعرف علي هذه القيم ودراستها وفههها والعمل علي تدعيمها والاستفادة منها في تعزيز عملية تحقيق أهداف مهنة الخدمة الاجتماعية... 4- قيم خاصة بالمجتمع : أن الن

وتتمثل فى أن الأخصائي الاجتماعي عليه أن يؤمن بأن للمجتمع قيمه وثقافته ( بما تشمله من عادات وتقاليد وأعراف وأسلوب للحياة...) التى تؤثر علي الأخصائي الاجتماعي بحكم أنه مواطن في هذا المجتمع ؛ وتؤثر علي عملاء الخدمة الاجتماعية بحكم أنهم أيضا مواطنين في هذا المجتمع ؛ وتؤثر علي المؤسسات القائمة في هذا المجتمع ، من منطلق أن هذه المؤسسات تعمل في بيئة محيطة بها ولابد أن تراعي قيم وثقافة هذه البيئة.... وأيا كان نوع القيم فإن الأخصائيين الاجتماعيين عليهم دراسة كل هذه القيم ، وفههها ، ومراعاة هذه القيم واحترامها عند تصميم وتخطيط وتنفيذ البرامج والخدمات ، والاستفادة منها في توجيه عملاء الخدمة الاجتماعية ، وفي تدعيم الممارسة المهنية لتحقيق أهداف الخدمة الاجتماعية. 


\section{أمثلة علي بعض القيم والأخلاقيات المهنية في الخدمة الاجتماعية :}

لمهنة الخدمة الاجتماعية العديد من القيم والأخلاقيات العامة والمهنية التي تؤمن بها وتلتزم بها وتطبقها عند التعامل مع الناس بصفة عامة وعملاء الخدمة الاجتماعية بصفة خاصة . ومن هذه القيم والأخلاقيات نذكر : الحرية والمشاركة والعدالة الاجتماعية وحق تقرير المصير والنسبية والأمانة والنزاهة وقدرة العميل والكرامة الإنسانية وقبل الاختلافات وضرورة اشباع الاحتياجات الإنسانية الرئيسية ... ويمكن عرض بعض ولاهن هذه القيم والأخلاقيات بشيء

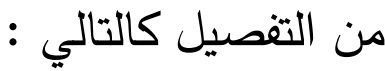

1- الإيمان بجميع حقوق الإنسان وعلي رأسها حقه في الحياة والنمو والتعليم والعمل

$$
\text { والحرية .... }
$$

2- الإيمان بقيمة الفرد وكرامته .

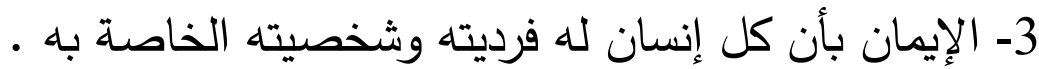

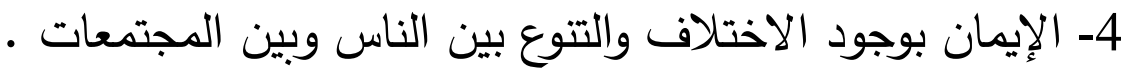

5- الإيمان بالفروق الفردية سواء بين الأفراد أو الجماعات أو الدنظمات أو المجتمعات الإت التعات

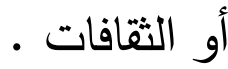

6- الإيمان بعدم التمييز السلبي أو التترقة السلبية بين الناس لأي سبب ، سواء كان هذا

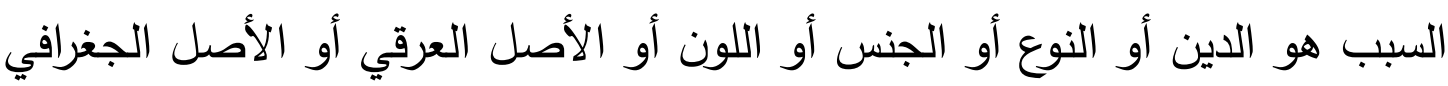

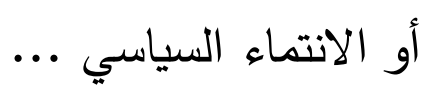

7- الإيمان بحق الفرد بممارسة حريته في حدود القيم المجتمعية. 8- الإيمان بحق الفرد في تقرير مصيره مع عدم الاضرار بحقوق الغير. 9- تئمن مهنة الخدمة الاجتماعية بالثوري وبالمشاركة والديموقراطية. 10- تؤمن الخدمة الاجتماعية بالمساواة الاجتماعية بين الناس.

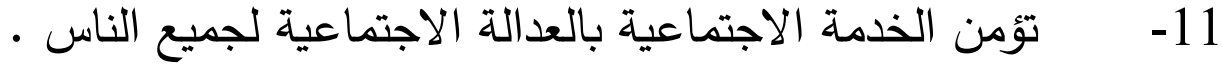

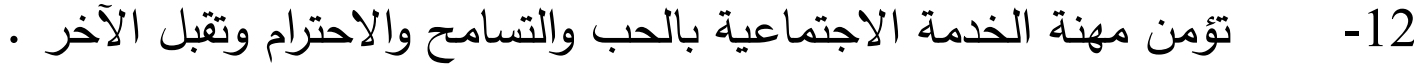

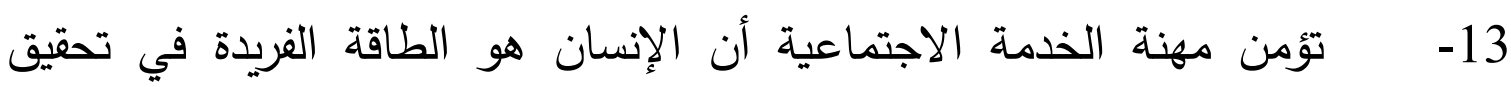
الاستقرار الاجتماعي وفي احداث التغير الاجتماعى في المجتمع. الاعن. 
وعلي جميع الأخصائيين الاجتماعيين الالتزام والاسترشاد بهذه القيم والأخلاقيات ومراعاتها

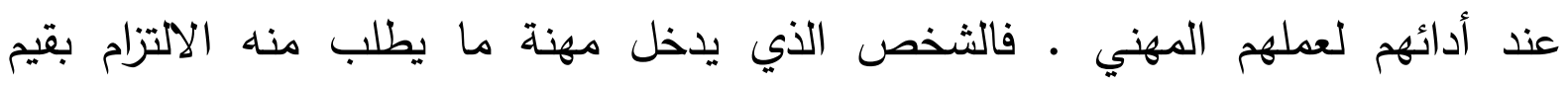

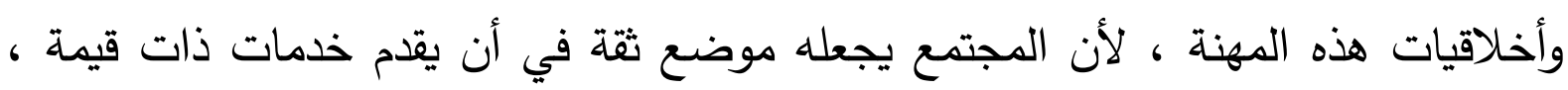

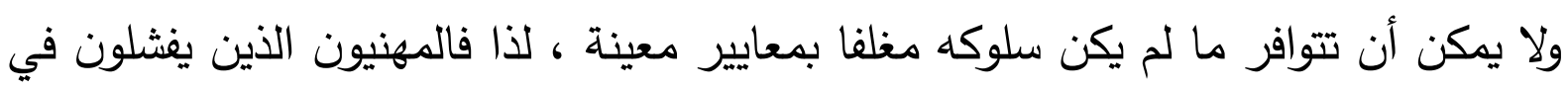

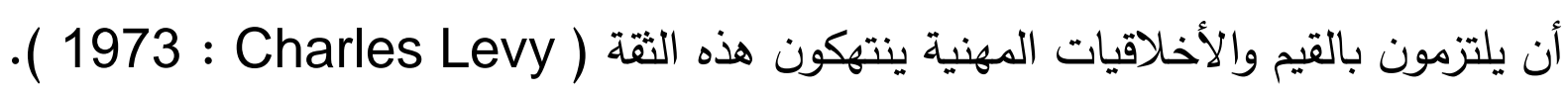

هذا ولقد حددت الجمعية القومية للأخصائيين الاجتماعين بالولايات المتحدة الأمريكية

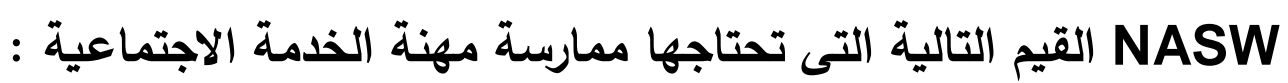
1- قيمة حق تقرير المصير للعملاء بقدر الإمكان. 2- قيمة تقديم الذدمات الاجتماعية والعلاج بصورة محترمة لكرامة العملاء بغض فئن

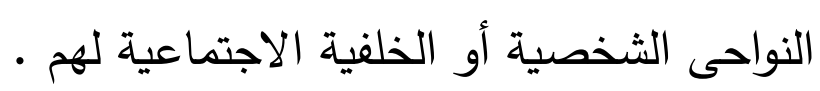

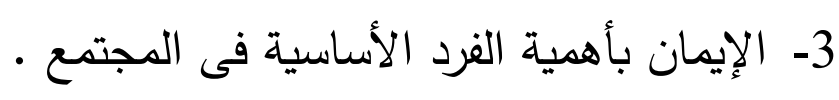

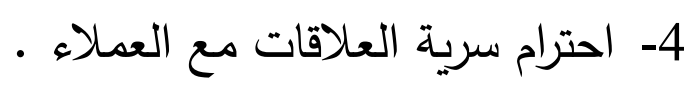
5- الإيمان بأهمية التغيير الاجتماعي لدقابلة حاجات العملاء .

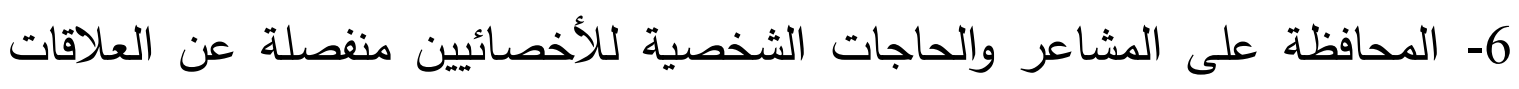

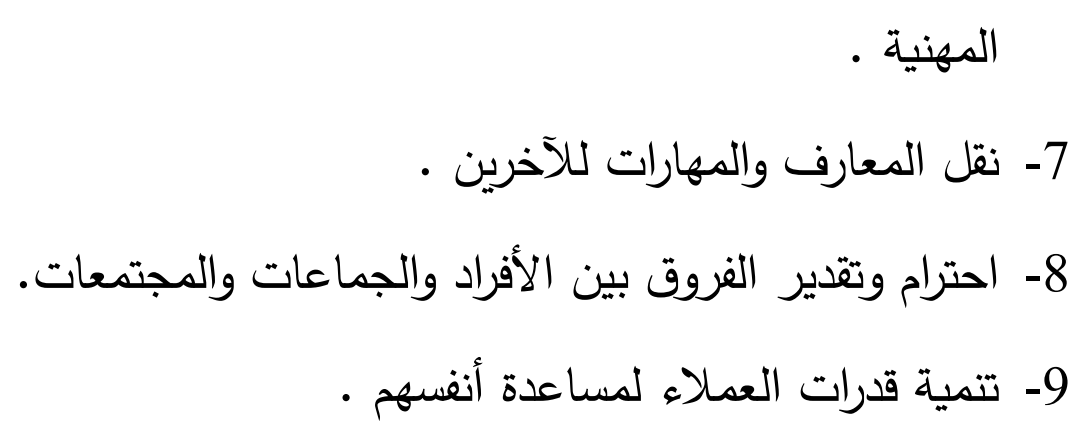
10- الإيمان بالعدالة الاجتماعية وضمان مستوى اقتصادي ومهنى وعقلى مناسب لكل

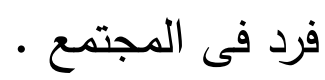

وفى تقرير أخر لنفس الجمعية، تم تديد القيم الأساسية للخدمة الاجتماعية فى الآتى: 1- الفرد أسمى ما فى الوجود وهو محور اهتمام المجتمع • 
2- الاعتماد المتبادل بين الأفراد فى المجتمع • 3- المسئولية المتبادلة بين الأفراد تجاه بعضهم البعض. 4- توجد احتياجات عامة لجميع البشر ، كما أن لكل شخص فرديته التى يجب مراعاتها 5- مسئولية المجتمع فى دعم قدرات الإنسان ومنحه فرص المشاركة الفعالة فى

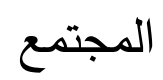
6- المجتمع مسئول عن إزالة العقبات التى تحول دون تحقيق الإنسان لذاته. كذلك حدد مجلس تعليم الخدمة الاجتماعية CSWE بالولايات المتحدة الأمريكية (1994) خمس فئات من القيم التي يجب غرسها في طلاب الخدمة الاجتماعية ويلتزم بها الأخصائيين الاجتماعيين ، هي كالتالي :

1- العلاقات المهنية بين الأخصائيين الاجتماعيين والعملاء والتي يجب الاجئ بنائها علي احترام قيمة وكرامة الإنسان والمشاركة المتبادلة والتقبل والثقة والأمانة والتتاول المسئول لموضوع الصراع في حال حدوثه . 2- الأخصائيون الاجتماعيون يجب أن يحترموا حق الأفراد في اتخاذ القرارات بشكل مستقل والمشاركة بشكل فاعل في عملية المساعدة. 3- الأخصائيون الاجتماعيون ملتزمون بمساعدة أنساق العملاء من الحصول علي علي

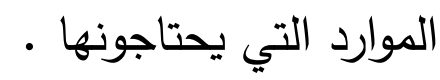
4- الأخصائيون الاجتماعيون عليهم بذل أقصي جها لجعل المؤسسات الاجتماعية أكثر إنسانية وأكثر استجابة للاحتياجات الإنسانية . 5- الأخصائيون الاجتماعيون عليهم احترام وتقبل الخصائص المتفردة للفئات السكانية المتتوعة .

مراجع الكتاب

$$
\text { 1. أولاً : المصادر }
$$


1-أحمد أمين : الأخلاق ( القاهرة : مكتبة النهضة المصرية للنشر والتوزيع ، 1967

2-أحمد زكي بدوي : معجم مصطلحات العلوم الاجتماعية ( لبنان : مكتبة لبنان للنشر

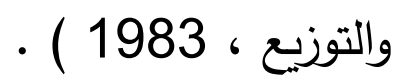

3-أحمد شفيق السكري : قاموس الخدمة الاجتماعية والخدمات الاجتماعية )

الإسكندرية : دار المعرفة الجامعية ، 2000 ) ) .

4-جاري ديسلر : إدارة الموارد البثرية ، ترجمة محمد سيد أحمد ( الرياض : دار الرئه المريخ .2003 ،

5-جيرالد جرينبرج وروبرت بارون : إدارة السلوك في المنظمات ، ترجمة رفاعي تحمد

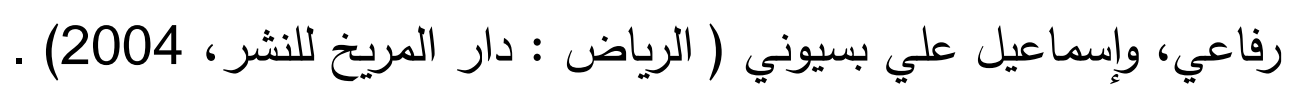

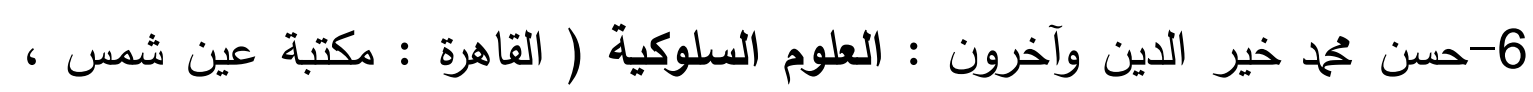

. $(2000$

7-ساندرا كان : المفاهيم الرئيسية في العلاقات العامة ، ترجمة مدحت محم أبو النصر

( القاهرة : المركز القومي للترجمة ، وزارة الثقافة المصرية ، 2014 ) ) .

8-سهام محمود العراقي : " الأخلاق المهنية .. منهجا دراسيا " ، جريدة الأهرام ،

القاهرة : 1 فبراير 2000.

9-سيد الهواري : الإدارة ، الأصول والأسس العلمية للقرن ال 21 ( القاهرة : مكتبة

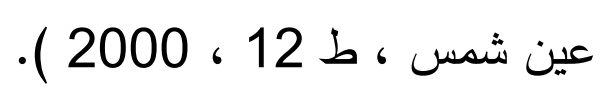

10- عبد العزيز عبد الله البريثن : " نحو تصور لصياغة دستور أخلاقي عربي

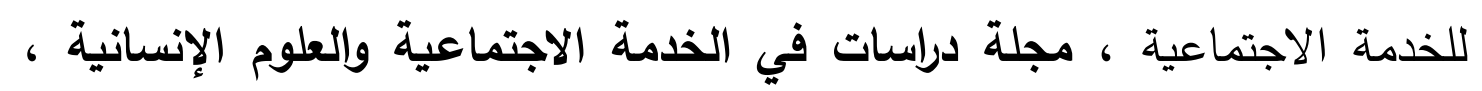

كلية الخدمة الاجتماعية ، جامعة حلوان ، عدد ابريل ، القاهرة : 2008.

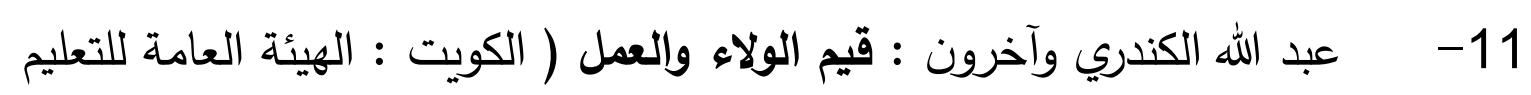

التطبيقي والتدريب ، 2008 ). 
12 - عرفات جبر وداود صنوبر : الاخلاقيات الادارية واثرها في الأداء المؤسسي ( نابلس : جامعة النجاح الوطنية، 2011 ).

13- مجمع اللغة العربية : المعجم الوجيز ( القاهرة : طبعة وزارة التربية والتعليم ، . ( 1999

14- محم التونجي: أخلاقيات المهنة والسلوك الاجتماعي ( عمان ، الاردن : دار وائل للنشر ، 2011 ) .

15- محمد بن أبي بكر عبد القادر الرازي : مختار الصحاح ( بيروت : مكتبة لبنان

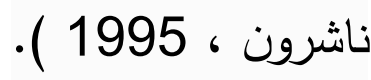

16- محم سلامة : النظام الاجتماعي والخلقي في الإسلام ( القاهرة : مكتبة الوفاء القانونية، 2012 ) • (10)

17- محم عبد الستار نصار : دراسات في فلسفة الأخلاق ( الكويت : دار القلم ، .) 1982

18- محمود عبد الفضيل : " أثر المتغيرات الاقتصادية علي قيم العمل واختياراته " ، ندوة القيم والاتجاهات ، المركز القومي للبحوث الجنائية والاجتماعية ، الجيزة : اكتوبر 1988.

Towards a Code of Ethics for Social : مدحت محم أبو النصر Workers in Egypt ، المجلة الاجتماعية القومية ، المركز القومي للبحوث الاجتماعية والجنائية ، مجلد 30 ، عدد 1 ، الجيزة : يناير 1993. 20 - مدحت محم أبو النصر : مفهوم ومراحل وأخلاقيات مهنة التدريب بالمنظمات

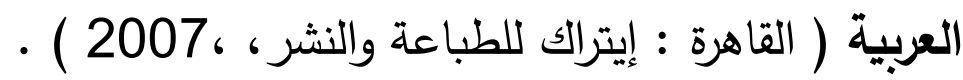
21- مدحت محم أبو النصر : قيم وأخلاقيات العمل والإدارة (الجيزة: الدار العالمية لاللشر والتوزيع، 2008) .

22 - مدحت محم أبو النصر : فن ممارسة مهنة الخدمة الاجتماعية ( القاهرة : دار الفجر للنشر والتوزيع ، 2009 ).

23- مدحت محمد أبو النصر : " دستور أخلاقي مهني للعاملين في جمعيات رعاية الأيتام بالمملكة العربية السعودية " ، ملتقي جمعيات رعاية الأيتام بالمملكة العربية 
السعودية ، جمعية تكافل الخيرية لرعاية الأيتام ، الدينة المنورة : 10-11 ديسمبر

" Current Trends in Social Work : مدحت محمد أبو النصر Education and Practice, With Special Reference to the Egyptian Experience

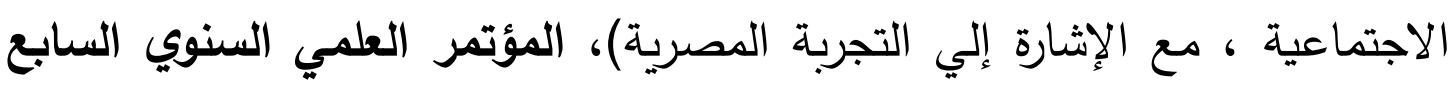

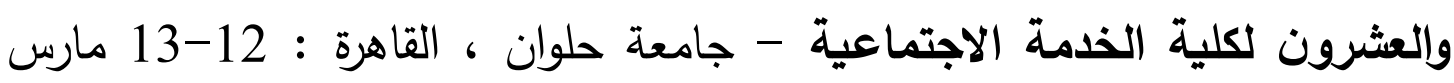
. 2014

25 - مدحت محم أبو النصر : الممارسة العامة للخدمة الاجتماعية من منظور

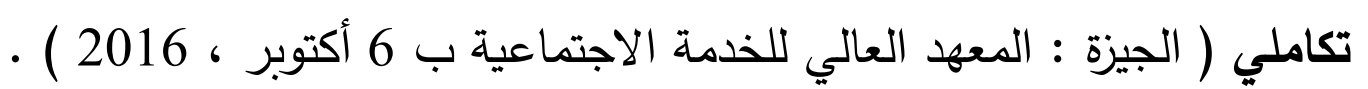

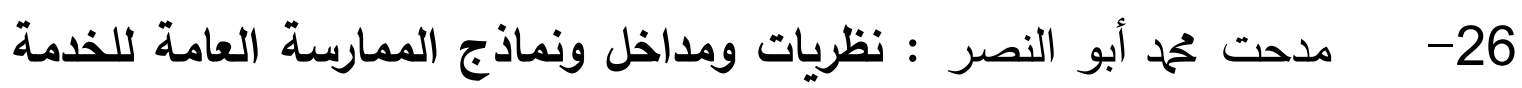
الاجتماعية ( دمنهور : المعهد العالي للخدمة الاجتماعية بدمنهور ، 2017 ) .

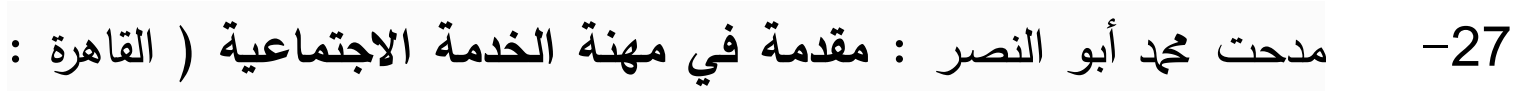
كلية الخدمة الاجتماعية ، كلية التربية ، جامعة حلوان ، 2019 ).

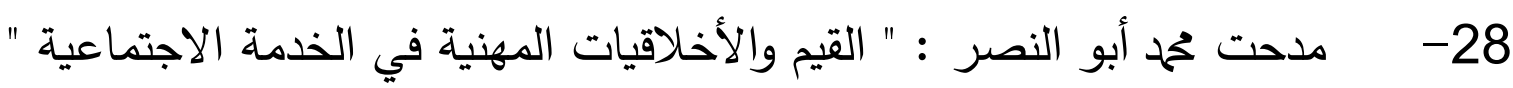
، مجلة القاهرة للذدمة الاجتماعية ، المعهة العالي للخدمة الاجتماعية بالقاهرة ، . 2019

29- مصطفى أبو بكر: أخلاقيات وقيم العمل ( الاسكندرية : الدار الجامعية ، . ( 2010

30- منير البعلبكي : قاموس المورد - إنجليزي/عربي ( بيروت : دار العلم للملايين للنشر والتوزيع ، 2019 ).

31- - نجم عبود نجم : أخلاقيات الإدارة في عالم متغير ( القاهرة : المنظمة العببية للتنمية الإدارية ، 2006 ) .

32 - يحيي حسن درويش : معجم مصطلحات الخدمة الاجتماعية ( القاهرة : الثركة المصرية العامة ، 1987 ). 
33- روجيه جارودي : الإسلام دين المستقبل ، ترجمة عبد المجيد البارودي ( القاهرة : دار الإيمان ، 2002 ).

34- وجيهة ثابت العاني : القيم التربوية وتصنيفاتها المعاصرة ( عمان : دار

$$
\begin{aligned}
& \\
& \\
& \text { ). }
\end{aligned}
$$

1- Allen Pincus \& Anne Minhan : Social Work Practice, Model and Methods ( III : F.E. Peacock Publishers, 1976 ).

2- Armando Morals \& Brodford W. Sheafor: Social Work, A Profession Of Many Faces (Boston Allyne \& Bacon, Inc., 2000 ).

3- BASW ( British Association of Social Workers in the UK ) ( 1975 , 2014 ) The Code of Ethics ( London : BASW Publications).

4- Beulah Compton : Introduction to Social Welfare \& Social Work ( N.Y. : The Doresy Press , 1980 )

5- Blanch Ken : Managing by Values ( USA : 1997 ).

6- BoB Lonne: "Ethical Practice in the Contemporary Human Services ", Social Work Journal , NASW , Vol. 4 , No., 46, 2004.

7- Brenda DuBois \& Karla Krogsurd Miley : Social Work, An Empowering Profession (Boston : PEARSON , 5 th. ed., 2005).

8- Charles Zastrow : Introduction to Social Work and Social Welfare (Belmont : Belmont Brooks ,Co., 2000).

9- David Watson (edr.) : A Code of Ethics for Social Work, The Second Step ( London: Routledge \& Kegan Paul and B.A.S.W., 1985 ).

10- E. P. Congress : Social work values and ethics ( Chicago: Nelson- Hall , 1999 ).

11- F. G. Reamer : " Ethical Issues in Direct Practice ", in P. Allen-Meares \& C. Garvin (edrs) : The handbook of social work direct practice ( California: Sage Publication, Inc. , 2000 ). 
12- F. G. Reamer : " Malpractice claims against social workers: First facts ", Social Work Journal , Vol. 40, 1995.

13- F. G. Reamer : Social work values and ethics ( N. Y. : Columbia University Press , 2006 ).

14- Hugo Reading : A Dictionary of the Social Sciences ( London : Routledge \& Kegan Paul, 1997 ).

15- Huw Richards: Social Work, Professional Social Workers and the Code of Ethics, in D. Watson (edr.) 1985 .

16- IFSW (International Federation of Social Workers) : Statement of Ethical Principles (2004).

17- IFSW (International Federation of Social Workers) : The International Code of Ethics for Social Workers (1976, , 2014, 2018 ).

18- IFSW (International Federation of Social Workers) : The International Code of Ethics for Social Workers (1976 , 2012,2014 ).

19- International Federation of Social Workers \& International Association of Schools of Social Work : "Ethics in Social Work, Statement of Principles, 2015.

20- J. Childs: Ethics in Business: Faith at Work (Minneapolis: Fortress Press, 1995).

21- Jerald Greenberg \& Robert A. Bron: Behavior in Organizations (N.J.: Prentice Hall, 2000).

22- Mattison, Marian : "Ethical Decision Making: The Person in the Process", Social Work Journal, May, Vol. 45, No. 3. , 2000.

23- Max Siporin : Introduction To Social Work ( N.Y.: Macmillan publication Co., Inc. $2^{\text {nd }}$. ed. , 1975).

24- Medhat Abo El Nasr: "Towards a Code of Ethics for Social Workers in Egypt “, The National Social Journal, The National Centre for Social Research , Vol. 30 , No. 1 , 1993 .

25- NASW (National Association of Social Workers in the USA) $(1960,2018)$ The Code of Ethics (Washington, D.C. : NASW. Publications). 
26- Robert Barker :The Social Work Dictionary ( Washington , D.C. : National Association of Social Workers , 5 th. ed. , 2003 ).

27- Rosalie Ambrosino \& et. al. : Social Work \& Social Welfare (Australia : Brooks/ COLE , 4 th. ed. , 2005 ).

28- Peter Drucker : Management, Tasks, Responsibilities

\& Practice ( N.Y.: Harper and Row. 1977 ) .

29- Sandra Cain : Key Concepts in Public Relations London : Palgrave \& Macmillan , 2009) .

30- Sissel Seim : "Rules of Ethics in Social Work ", Nordic Journal of Social Work, Vol. 1, in Swedish, Translated by Eva Westerberg a senior social worker in Sweden. (1986).

31- The Code of Ethics of Members of the American Association for Public Opinion Research (U.S.A : A.A.P.O.R. 1977) .

32- William E. Gordon : "Knowledge and Value: Their Distinction and Relationship in Clarifying Social Work Practice " , Social Work Journal , NASW press, Volume 10 , Issue 3 , July 1965.

33- Charles S. Levy : " The Value Base of Social Work ", Journal of Education for Social Work, Taylor \& Francis, Ltd. Council on Social Work Education, Vol. 9, No. 1 , WINTER 1973.

34- Pamela S. Landon with Marvin D. Feit : Generalist Social Work Practice ( N.Y. : Eddie Bowers Publishing , 1999 ). 35- Sarah Banks : Ethics and Values in Social Work (U.K. : Macmillan International , 4 th. ed. , 2009 ).

36- J. Barsky : Ethics and values in social work: An integrated approach for a Knowledge and Value: Their Distinction and Relationship in Clarifying Social Work Practice , 2010. 